\title{
Expression of CD137 and CD137 ligand in colorectal cancer patients
}

\author{
JAN DIMBERG $^{1}$, ANDERS HUGANDER ${ }^{2}$ and DICK WÅGSÄTER ${ }^{3}$ \\ ${ }^{1}$ Department of Natural Science and Biomedicine, University College of Health Sciences, Box 1026; ${ }^{2}$ Department of Surgery, \\ Ryhov County Hospital, SE-551 11 Jönköping; ${ }^{3}$ Atherosclerosis Research Unit, King Gustav V Research Institute, \\ Department of Medicine, Karolinska Institute, SE-171 76 Stockholm, Sweden
}

Received November 10, 2005; Accepted February 2, 2006

\begin{abstract}
The cytokine CD137, a member of the TNF receptor family, is expressed by $\mathrm{T}$ cells and regulates activation and proliferation of these cells. The CD137 ligand (CD137L) is expressed by antigen-presenting cells including macrophages, but also on various carcinoma cells. CD137/CD137L interaction plays a central role in sustaining $\mathrm{T}$ cell and macrophage activation, i.e. in antitumour immunity. The present study was designed to investigate whether CD137 and CD137L protein levels are altered in colorectal tumours compared with paired normal tissues. The CD137 and CD137L plasma levels from patients with colorectal cancer were also examined. Collectively, we noted a significantly lower CD137L level in cancerous tissue compared with paired normal tissue, and the difference in CD137L protein level was significantly lower in the colon cancer subgroup compared with paired normal colon tissue. On the other hand, we found an elevated CD137 protein level in the rectal cancer subgroup compared with paired normal rectal tissue. Patients with a tumour localised in the colon revealed significantly higher soluble CD137 protein concentration in the plasma than patients with a tumour localised in the rectum, and there was a tendency toward a higher concentration of CD137L protein in the plasma from patients with tumour localised in the colon. Moreover, the plasma concentrations of CD137 and CD137L proteins were strongly and significantly correlated. The different expression levels of CD137 and CD137L in the colon and rectum may reflect divergent mechanisms involved in the pathogenesis of colorectal cancer and lead to dissimilar protective immunity.
\end{abstract}

Correspondence to: Dr Jan Dimberg, Department of Natural Science and Biomedicine, University College of Health Sciences, Box 1026, SE-551 11 Jönköping, Sweden

E-mail: jan.dimberg@hhj.hj.se

Key words: CD137, CD137L, protein expression, colorectal cancer, cytokines

\section{Introduction}

Tumour-associated leukocytes such as monocytes/macrophages and T-cells can be tumouricidal by attacking neoplastic cells and/or producing cytokines that can promote or inhibit tumour progression $(1,2)$.

CD137 (4-1BB) is a receptor belonging to the TNF receptor family. CD137 is expressed by activated T lymphocytes, and regulate activation and proliferation of $\mathrm{T}$ cells $(3,4)$. However, the expression of CD137 is not restricted to immune cells; its expression has also been demonstrated on endothelial and smooth muscle cells (5-7). The CD137 ligand (CD137L/ $4-1 B B L)$ is expressed and released by activated antigenpresenting cells, including macrophages and B cells, and binding to its receptor results in IL- 2 and IFN- $\gamma$ production by $\mathrm{T}$ cells $(8,9)$.

A bi-directional transduction of signal exists for the CD137/CD137L system, resulting in B-cell proliferation and the secretion of cytokines and chemokines from macrophages such as IL-6 and IL-8 $(4,10)$. It has been reported that $\mathrm{CD} 137 \mathrm{~L}$ is expressed to a varying extent on several human colon carcinoma cell lines, as well as on cells obtained from patient tumours (11). In addition, the CD137/CD137L interaction appears to induce the chemokine IL-8 (CXCL8) production from these carcinoma cells. Different chemokines (chemotactic cytokines) are variably expressed in a number of cancers and provide the directional stimulus for the movement of leukocytes in cancers (12). Chemokines are major determinants of macrophage and lymphocyte infiltration in human carcinomas (12). Furthermore, another study demonstrated that IL-8 expression was significantly higher in human colorectal cancer compared with paired normal mucosa (13).

To our knowledge, there have been no reports on CD137 and CD137L levels in human colorectal cancer. In this study, we measured the CD137 and CD137L levels in cancerous and paired normal tissues and in plasma from patients with colorectal cancer. We also analysed these levels in relation to the clinicopathological findings.

\section{Materials and methods}

Patients and tissue sampling. This study comprised tissue samples, which were obtained from 76 patients who underwent 
surgical resections for primary colorectal adenocarcinomas diagnosed at the Department of Surgery, Ryhov County Hospital, Jönköping, Sweden. Sporadic tumours from 76 subjects (40 male and 36 female) with a mean age of 70 years (range, 36-93) were collected and classified according to Dukes' classification system: stage A $(n=11)$, stage B $(n=31)$, stage $C(n=29)$ and stage $D(n=5)$. The tumours were localised in the colon $(n=36)$ and rectum $(n=40)$. From each patient tumour tissue and adjacent normal mucosa (about $5 \mathrm{~cm}$ from the tumour) were excised and immediately frozen at $-70^{\circ} \mathrm{C}$ until analysis.

Plasma samples. A total of 44 patients ( 21 colon cancers and 23 rectal cancers) were available for plasma collection. Venous blood was collected before surgery and separated by centrifugation within $1 \mathrm{~h}$. Plasma was removed and stored at $-70^{\circ} \mathrm{C}$ until assayed.

Protein preparation. Frozen tumour tissue and normal mucosa were thawed and homogenised in ice-cold lysis buffer containing PBS (9.1 mM dibasic sodium phosphate, $1.7 \mathrm{mM}$ monobasic sodium phosphate, $150 \mathrm{mM} \mathrm{NaCl}, \mathrm{pH}$ 7.4) and $1 \%$ Nonidet P-40, $0.5 \%$ sodium deoxycholate, $0.1 \%$ sodium dodecyl sulphate (SDS), $100 \mu \mathrm{g} / \mathrm{ml}$ phenylmethylsulphonyl fluoride (PMSF), $2 \mu \mathrm{g} / \mathrm{ml}$ aprotinin, $1 \mathrm{mM}$ sodium orthovanadate and $1 \mu \mathrm{g} / \mathrm{ml}$ leupeptin. The lysate was placed on ice for $30 \mathrm{~min}$, then centrifuged at $13000 \mathrm{x} \mathrm{g}$ for $10 \mathrm{~min}$. Protein content of the supernatant fluid was determined for each sample using the Lowry assay (14).

ELISA. The CD137 and CD137L protein levels of cancer and paired normal tissues from 76 patients were measured using enzyme-linked immunosorbent assay (ELISA) according to the manufacturer's recommendations (R\&D Systems, Minneapolis, MN, USA). Plasma levels of the CD137 and CD137 ligands were also measured from 44 corresponding cancer patients. For CD137 (DY838), goat anti-human CD137 antibody was used as the capture antibody, and biotinylated goat anti-human CD137 antibody as the detection antibody. For CD137 ligand, goat anti-human CD137 ligand (AF2295) antibody was used as the capture antibody, and biotinylated goat anti-human CD137 ligand antibody (BAF2295) as the detection antibody. The CD137 and CD137L protein levels were expressed as $\mathrm{pg} / \mathrm{mg}$ of protein, and the plasma concentration was expressed as $\mathrm{pg} / \mathrm{ml}$. All analyses were performed in duplicate, and the mean values were used for statistical calculations.

Statistical analysis. The Student's t-test was used to analyse CD137 and CD137L data, which are expressed as mean values \pm standard error of the mean (SEM). Correlations were analysed with Spearman's coefficient analysis. Statistical analysis was performed using SPSS for Windows (release 11.5, 2002; SPSS Inc., Chicago, IL). Results were considered significant at a level of $\mathrm{P}<0.05$.

\section{Results}

Protein levels of CD137 in colorectal tissue. CD137 protein concentration was measured by ELISA in protein lysates of

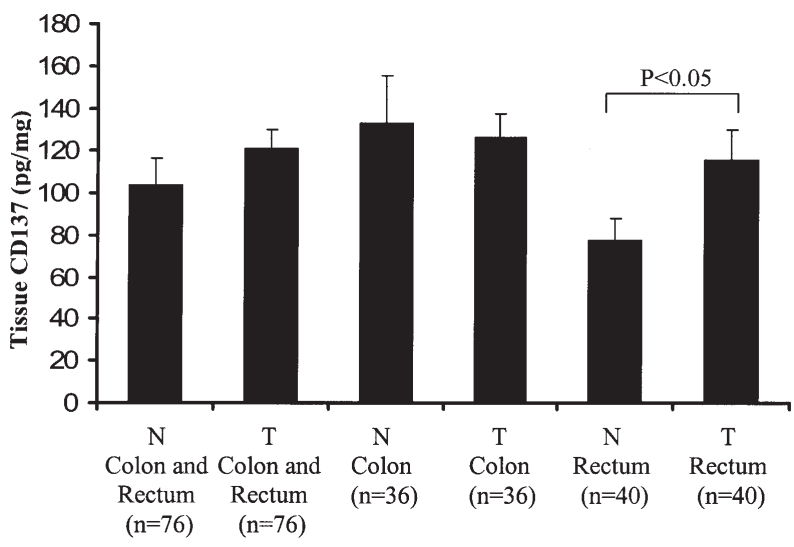

Figure 1. Relationship between CD137 protein levels in human colorectal cancer $(\mathrm{T})$ and paired normal tissue $(\mathrm{N})$. The tissue level of CD137 protein in rectal cancer has a significantly higher value compared with paired normal tissue. The difference of CD137 protein level between total tumours and paired normal tissues and the colon cancer subgroup was not significant.

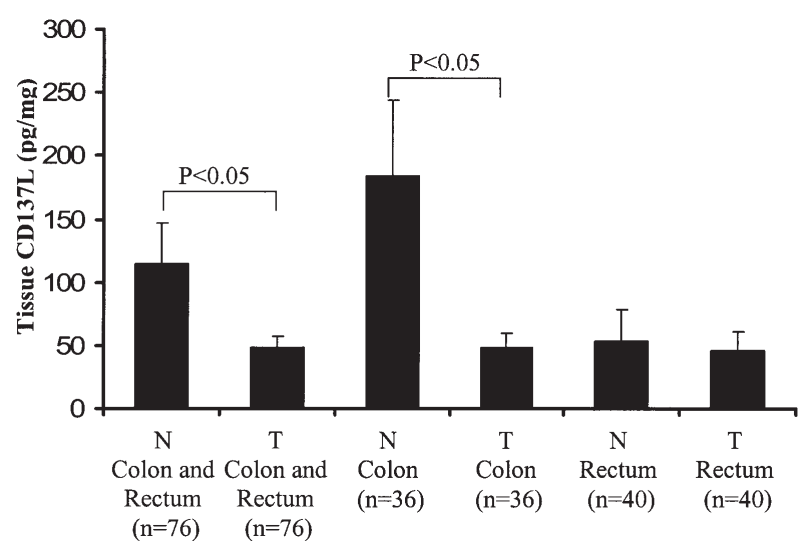

Figure 2. Relationship between CD137L protein levels in human colorectal cancer $(\mathrm{T})$ and paired normal tissue $(\mathrm{N})$. The tissue level of CD137L protein in the total tumours and the colon cancer subgroup was significantly lower compared with paired normal tissues. The tissue level of CD137L protein in rectal cancer was not significantly different compared with paired normal tissue.

cancerous colorectal tissues and matched normal tissues from 76 patients. Evaluation of the relative CD137 expression (tumour vs. normal tissue) showed 57.9\% (44/76) up-regulation and $42.1 \%$ (32/76) suppression. The levels of CD137 protein in cancerous tissue $(121 \pm 9.0 \mathrm{pg} / \mathrm{mg})$ were not different from normal tissue (104 $\pm 12.3 \mathrm{pg} / \mathrm{mg}$ ) (Fig. 1).

When subdividing the patients into groups of colon $(n=36)$ and rectum $(n=40)$ cases, we found an up-regulation in $55.6 \%(20 / 36)$ of cases and suppression in $44.4 \%(16 / 36)$ of cases in colon comparing cancer tissue with adjacent normal tissue (Fig. 1). The CD137 protein level in cancerous colon tissue $(126 \pm 11.6 \mathrm{pg} / \mathrm{mg})$ was nearly the same as that in normal colon tissue $(133 \pm 22.7 \mathrm{pg} / \mathrm{mg})$. In the rectum, $62.5 \%$ $(25 / 40)$ of cases were up-regulated and $37.5 \%(15 / 40)$ of cases were suppressed when comparing the CD137 protein expression in tumours with adjacent normal tissue. The CD137 protein level in cancerous rectal tissue $(116 \pm 13.7 \mathrm{pg} / \mathrm{mg})$ was significantly higher $(\mathrm{P}<0.05)$ compared with the level in normal rectal tissue $(78 \pm 9.9 \mathrm{pg} / \mathrm{mg})$ (Fig. 1). 


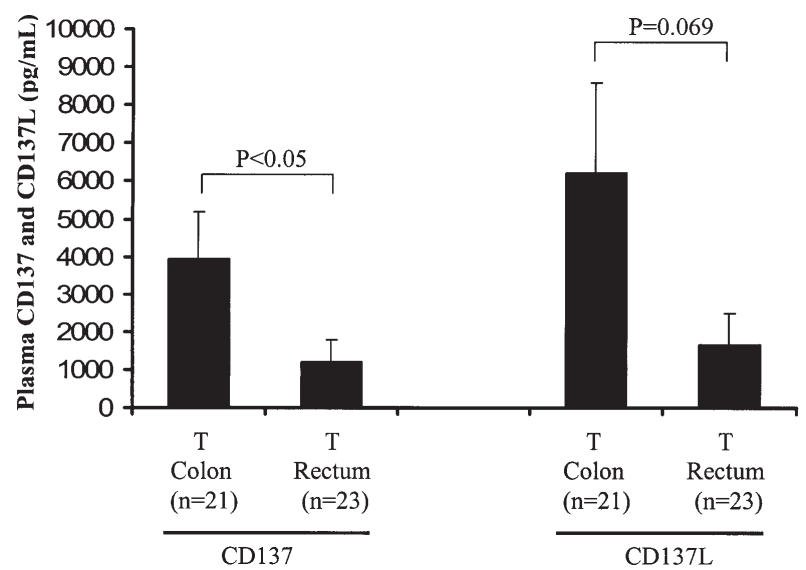

Figure 3. Plasma CD137 and CD137L protein concentration in human colorectal cancer. Colon cancer patients have a significantly higher CD137 protein concentration compared with rectal cancer patients. The plasma concentration of CD137L tends to be higher in colon cancer patients compared with rectal cancer patients.

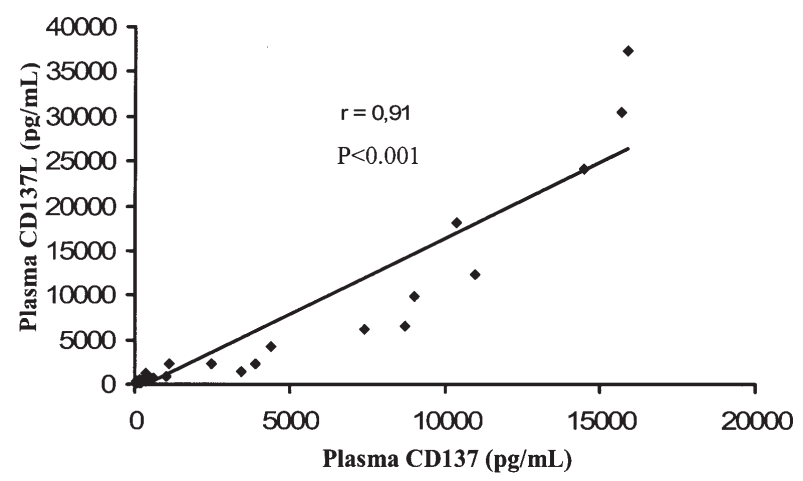

Figure 4. Correlation between CD137L and CD137 concentrations in the plasma of colorectal cancer patients.

Protein levels of CD137L in colorectal tissue. CD137L protein concentration was measured by ELISA in proteinlysates of cancerous colorectal tissues and matched normal tissues from 76 patients. We found undetectable CD137L protein expression in $19.7 \%$ (15/76) of colorectal cancer, as well as corresponding normal tissue ( 7 cases located in the colon and 8 cases located in the rectum), and up-regulation and suppression in $36.8 \%(28 / 76)$ and $43.4 \%(33 / 76)$ respectively. There was a significantly lower $(\mathrm{P}<0.05)$ protein expression of CD137L in cancerous tissue $(48 \pm 9.2 \mathrm{pg} / \mathrm{mg})$ compared with normal tissue $(115 \pm 32.3 \mathrm{pg} / \mathrm{mg})$ (Fig. 2).

When subdividing the patients (Fig. 2) into groups of colon $(n=36)$ and rectum $(n=40)$ cases, the relative CD137L expression (tumour vs. normal tissue) was up-regulated in $30.6 \%(11 / 36)$ and suppressed in $50 \%(18 / 36)$ of the colon subgroup. The level of CD137L protein concentration in colon cancer $(49 \pm 11.1 \mathrm{pg} / \mathrm{mg})$ was significantly lower $(\mathrm{P}<0.05)$ when compared with normal adjacent tissue $(184 \pm 60.6 \mathrm{pg} / \mathrm{mg})$ (Fig. 2). In the rectal cancer subgroup, the CD137L protein level $(46 \pm 14.6 \mathrm{pg} / \mathrm{mg})$ was not significantly different compared with the level in normal rectal tissue $(53 \pm 25.5 \mathrm{pg} / \mathrm{mg})$ (Fig. 2).

Protein levels of CD137 and CD137L in plasma from colorectal patients. The plasma levels of CD137 was significantly higher $(\mathrm{P}<0.05)$ in colon cancer patients $(3931 \pm 1268 \mathrm{pg} / \mathrm{ml})$ compared with that in rectal cancer patients $(1194 \pm 581 \mathrm{pg} / \mathrm{ml})$. The plasma levels of CD137L tended to be higher $(\mathrm{P}=0.069)$ in patients with a tumour localised in the colon $(6206 \pm 2392 \mathrm{pg} / \mathrm{ml})$ compared with the rectum $(1674 \pm 800 \mathrm{pg} / \mathrm{ml})$ (Fig. 3). Furthermore, the plasma levels of CD137 and CD137L of the entire patient collective were significantly correlated $(\mathrm{r}=0.911, \mathrm{P}<0.001)$ (Fig. 4).

The levels of CD137 and CD137L protein in all analysed tissues and plasma did not correlate with clinical characteristics such as age, gender and Dukes' stage (data not shown).

\section{Discussion}

It is hypothesized that cancers are normally eliminated by immune responses. Tumours contain leukocytes that have infiltrated the tumour and are involved in the antitumour response $(1,2)$.

CD137 has been found on activated $\mathrm{T}$ cells positive for CD4/CD8, $(3,4)$. The CD137 ligand (CD137L) is expressed and released by activated antigen-presenting cells such as macrophages and B cells. CD137 signalling is very complex. Ligation of CD137 with CD137L plays an important role in sustaining $\mathrm{T}$ cell activation and proliferation by amplifying the cytotoxic T lymphocyte response. However, CD137 ligation has also been found to inhibit proliferation and induce apoptosis $(4,15,16)$. CD137/CD137L also causes the proliferation or apoptosis of B cells $(10,17)$.

In this study, the protein level of CD137 and CD137L was determined in colorectal cancer and paired normal tissue. Collectively, we noted a significantly lower CD137L level in cancerous tissue and a significantly lower CD137L level in colon cancer compared with paired normal tissue. We did not observe a significant difference regarding CD137L expression in the rectal cancer subgroup compared with paired normal rectal tissue. A similar difference for CD137 in cancerous colorectal tissue was not observed. However, we found a significantly higher CD137 level in the cancerous rectal tissue compared with paired normal rectal tissue. The differences regarding CD137 and CD137L expression in tumours from the colon and rectum may reflect a different mechanism involved in the pathogenesis of cancer in colon and rectum. It has been reported that there may be a difference in the carcinogenesis of colorectal cancers based on the tumour location (18). The discrepancy of CD137 and CD137L expression that we demonstrated may in part be explained by different tumour immunity between the two types of location.

Tumour-infiltrating leukocytes including $\mathrm{T}$ cells and macrophages could at least in part be modulated by molecules from tumour cells following differential expression of CD137 and CD137L. It has been reported that CD137L is expressed on varying human colon carcinoma cell lines (11). To our knowledge, no studies have been published on the expression of CD137L in rectal carcinoma cell lines or rectal tumours. Our results indicate a suppressed level of CD137L in colon cancer. This phenomenon may be involved in the escape of tumours from immune surveillance resulting in decreased $\mathrm{T}$ cell-colon tumour and $\mathrm{T}$ cell-macrophage interactions following a low antitumour immune response. Moreover, we showed an up-regulated level of CD137 in 
rectal cancer, which possibly means a higher protective immunity against the rectal tumour via $\mathrm{T}$ cell-macrophage interaction.

Soluble CD137 and CD137L did not seem to be selective for a specific disease, and can be detected in high levels in the sera of patients with several diseases. Elevated soluble forms of CD137 are found in the sera of patients with rheumatoid arthritis (RA) $(19,20)$ and leukemia $(21)$. Moreover, soluble CD137L in sera is enhanced from patients with RA (19) and haematological malignancies (9). Soluble CD137 is released by activated $\mathrm{T}$ cells and has been shown to be involved in negative feedback control of the inflammation response, and the level of soluble CD137 is inversely correlated with $\mathrm{T}$ cell proliferation (20). Likewise, soluble CD137L has been suggested to control $\mathrm{T}$ cell function by inhibiting the CD137-CD137L interaction in an antagonistic manner (19). In the present study, we showed that the plasma levels of soluble CD137 and CD137L is higher in patients with colon cancer than in patients with rectal cancer. Interestingly, CD137 and CD137L levels were strongly and significantly correlated $(\mathrm{r}=0.911, \mathrm{P}<0.001)$ and may indicate a feedback loop to reduce further activation.

It is important to investigate whether CD137/CD137L is related to colorectal carcinogenesis and carries significant clinical relevance. Further studies are being performed in our laboratory to clarify the influence of immunological features in colorectal cancer.

\section{Acknowledgements}

This work was supported by grants from the County Council of Jönköping, Sweden and the University College of Health Sciences, Jönköping, Sweden.

\section{References}

1. Balkwill F and Mantovani A: Inflammation and cancer: back to Virchow? Lancet 357: 539-545, 2001.

2. Coussens LM and Werb Z: Inflammation and cancer. Nature 420: 860-867, 2002.

3. Pollok KE, Kim SH and Kwon BS: Regulation of 4-1BB expression by cell-cell interactions and the cytokines, interleukin-2 and interleukin-4. Eur J Immunol 25: 488-494, 1995.

4. Langstein J, Michel J, Fritsche J, Kreutz M, Andreesen R and Scwarz H: CD137 (ILA/4-1BB), a member of the TNF receptor family regulates monocyte activation via bidirectional signaling. J Immunol 160: 2488-2492, 1998.
5. Boussaud V, Soler P, Moreau J, Goodwin RG and Hance AJ: Expression of three members of the TNF-R family of receptors (4-1BB, lymphotoxin-beta receptor and Fas) in human lung. Eur Respir J 12: 926-931, 1998

6. Broll K, Richter G, Pauly S, Hofstaedter F and Schwarz H: CD137 expression in tumor vessel walls. High concentration with malignant tumors. Am J Clin Pathol 115: 543-549, 2001.

7. Seko Y, Sugishita K, Sato O, Takagi A, Tada Y, Matsuo H, Yagita H, Okumura K and Nagai R: Expression of costimulatory molecules (4-1BBL and Fas) and major histocompatibility class I chain-related A (MICA) in aortic tissue and Takayasu's arteritis. J Vasc Res 41: 84-90, 2004

8. Cannons JL, Hoeflich KP, Woodgett JR and Watts TH: Role of the stress kinase pathway in signaling via the $\mathrm{T}$ cell costimulatory receptor 4-1BB. J Immunol 163: 2990-2998, 1999.

9. Salih HR, Schmetzer HM, Burke C, Starling GC, Dunn R, Pelka-Fleischer R, Nuessler V and Kiener PA: Soluble CD137 (4-1BB) ligand is released following leukocyte activation and is found in sera of patients with hematological malignancies. J Immunol 167: 4059-4066, 2001.

10. Pollok KE, Kim Y-J, Hurtado JC, Zhou Z, Kim KK and Kwon BS: 4-1BB T cell antigen binds to mature B cells and macrophages and co-stimulates anti- $\mu$ primed splenic B cells. Eur J Immunol 24: 367-374, 1994.

11. Salih HR, Kosowski SG, Haluska VF, Starling GC, Loo DT, Lee F, Aruffo AA, Trail PA and Kiener PA: Constitutive expression of functional 4-1BB (CD137) ligand on carcinoma cells. J Immunol 165: 2903-2910, 2000.

12. Balkwill F: Chemokine biology in cancer. Semin Immunol 15: 49-55, 2003.

13. Baier PK, Eggstein S, Wolff-Vorbeck G, Baumgartner U and Hopt UT: Chemokines in human colorectal carcinoma. Anticancer Res 25: 3581-3584, 2005.

14. Bollag DM, Rozycki MD and Edelstein SJ: Protein Methods. Wiley-Liss, New York, 1996.

15. DeBenedette MA, Shahinian A, Mak TW and Watts TH: Costimulation of CD28-T lymphocytes by 4-1BB ligand. J Immunol 158: 551-559, 1997.

16. Michel J, Pauly S, Langstein J, Krammer PH and Schwarz H: CD137-induced apoptosis is independent of CD95. Immunology 98: 42-46, 1999.

17. Kienzle G and von Kempis J: CD137 (ILA/4-1BB) expressed by primary human monocytes induces monocyte activation and apoptosis of B lymphocytes. Int Immunol 12: 73-82, 2000.

18. Konishi K, Fujii N, Boku S, Kato I, Ohtsu A, Tajiri H, Ochiai A and Yoshida S: Clinicopathological differences between colonic and rectal carcinomas: are they based on the same mechanism of carcinogenesis? Gut 45: 818-821, 1999

19. Jung HW, Choi SW, Choi JI and Kwon BS: Serum concentrations of soluble 4-1BB and 4-1BB ligand correlated with the disease severity in rheumatoid arthritis. Exp Mol Med 36: 13-22, 2004.

20. Michel J and Schwarz H: Expression of soluble cd137 correlates with activation-induced cell death of lymphocytes. Cytokine 12: 742-746, 2000.

21. Furtner M, Straub RH, Kruger S and Schwarz H: Levels of soluble CD137 are enhanced in sera of leukemia and lymphoma patients and are strongly associated with chronic lymphocytic leukemia Leukemia 19: 883-885, 2005. 